\title{
The Willow Microbiome Is Influenced by Soil Petroleum-Hydrocarbon Concentration with Plant Compartment-Specific Effects
}

\author{
Stacie Tardif ${ }^{1,2 *}$, Étienne Yergeau ${ }^{3,4}$, Julien Tremblay ${ }^{3}$, Pierre Legendre ${ }^{5}$, Lyle G. Whyte ${ }^{1}$ \\ and Charles W. Greer ${ }^{1,3}$ \\ ${ }^{1}$ Department of Natural Resource Sciences, McGill University, Sainte-Anne-de-Bellevue, QC, Canada, ${ }^{2}$ Section of Microbial \\ Ecology and Biotechnology, Department of Plant and Environmental Sciences, University of Copenhagen, Copenhagen, \\ Denmark, ${ }^{3}$ Energy, Mining, and Environment, National Research Council Canada, Montréal, QC, Canada, ${ }^{4}$ Centre \\ INRS-Institut Armand-Frappier, Institut national de la recherche scientifique, Laval, QC, Canada, ${ }^{5}$ Département de Sciences \\ Biologiques, Université de Montréal, Montréal, QC, Canada
}

\section{OPEN ACCESS}

Edited by: Eric Altermann,

AgResearch, New Zealand

Reviewed by:

Naresh Singhal,

University of Auckland, New Zealand

David Dowling,

Institute of Technology Carlow, Ireland

Frederick Ato Armah,

University of Cape Coast, Ghana

*Correspondence:

Stacie Tardif

stta@plen.ku.dk

Specialty section:

This article was submitted to Microbiotechnology, Ecotoxicology

and Bioremediation,

a section of the journal

Frontiers in Microbiology

Received: 16 June 2016

Accepted: 17 August 2016

Published: 08 September 2016

Citation

Tardif S, Yergeau É, Tremblay J, Legendre $P$, Whyte LG and Greer CW

(2016) The Willow Microbiome Is Influenced by Soil

Petroleum-Hydrocarbon

Concentration with Plant Compartment-Specific Effects.

Front. Microbiol. 7:1363.

doi: 10.3389/fmicb.2016.01363
The interaction between plants and microorganisms, which is the driving force behind the decontamination of petroleum hydrocarbon $(\mathrm{PHC})$ contamination in phytoremediation technology, is poorly understood. Here, we aimed at characterizing the variations between plant compartments in the microbiome of two willow cultivars growing in contaminated soils. A field experiment was set-up at a former petrochemical plant in Canada and after two growing seasons, bulk soil, rhizosphere soil, roots, and stems samples of two willow cultivars (Salix purpurea cv. FishCreek, and Salix miyabeana CV. SX67) growing at three PHC contamination concentrations were taken. DNA was extracted and bacterial 16S rRNA gene and fungal internal transcribed spacer (ITS) regions were amplified and sequenced using an lon Torrent Personal Genome Machine (PGM). Following multivariate statistical analyses, the level of PHC-contamination appeared as the primary factor influencing the willow microbiome with compartment-specific effects, with significant differences between the responses of bacterial, and fungal communities. Increasing PHC contamination levels resulted in shifts in the microbiome composition, favoring putative hydrocarbon degraders, and microorganisms previously reported as associated with plant health. These shifts were less drastic in the rhizosphere, root, and stem tissues as compared to bulk soil, probably because the willows provided a more controlled environment, and thus, protected microbial communities against increasing contamination levels. Insights from this study will help to devise optimal plant microbiomes for increasing the efficiency of phytoremediation technology.

Keywords: contamination, endophytes, microbiome, phytoremediation, rhizosphere, willow

\section{INTRODUCTION}

Phytoremediation exploits the relationships between plants and their associated microbial communities to remediate contaminated environments. This cost- and energy-efficient technology offers a promising solution to the problem of worldwide soil pollution. The lengthy remediation rates associated with this technology, however, have severely impeded its capacity to compete on 
the market and have frequently been linked to the insufficient establishment of plant and microbial biomass (Huang et al., 2004; Sun et al., 2011) and/or the selection of suboptimal plant microbiomes (Siciliano et al., 2003; Bell et al., 2014a,b).

The plant microbiome is comprised of archaeal, bacterial, and fungal communities that are associated with the host in the rhizosphere (soil directly attached to the plant-root interface), phyllosphere (aboveground parts of plants), and endosphere (interior tissue of plants; Kowalchuk et al., 2010; Schlaeppi and Bulgarelli, 2014). The breakdown of organic pollutants such as petroleum hydrocarbons (PHCs), including polycyclic aromatic hydrocarbons (PAHs), in phytoremediation technology is driven by the interaction between the plants, and microorganisms (El Amrani et al., 2015). The stimulated microorganisms use organic contaminants as carbon and/or energy sources and in the process, partially, or completely breakdown these compounds into less toxic or less available substrates in the environment (Reichenauer and Germida, 2008). These processes occur within the plant itself but more commonly within the rhizosphere. The rhizosphere provides a favorable physical and chemical environment in which microorganisms strive resulting in increased microbial biomass and activity (Günther et al., 1996). This environment often boosts higher nutrient concentrations than the surrounding bulk soil due to the release of plant exudates, which are comprised of an array of different organic compounds including amino acids, flavonoids, aliphatic acids, organic acids, proteins, and fatty acids (Berg et al., 2005; el Zahar Haichar et al., 2008). Many of these plant secondary metabolites are structurally similar to organic contaminants (Singer et al., 2003) and as a result, the expression of hydrocarbon degradation genes is generally elevated in the rhizosphere (Yergeau et al., 2014), which increases degradation (Reichenauer and Germida, 2008). Several studies have shown that organic compounds such as PHCs (Yateem et al., 1999) and PAHs (Pradhan et al., 1998) are degraded more rapidly by rhizosphere communities than by surrounding bulk soil communities.

Endophytic microorganisms colonize the endosphere without harming their plant host. These microorganisms have been shown to metabolize pollutants and to impact plant fitness (Taghavi et al., 2005). Endophytes also often have plant growth promoting capacity, through nitrogen fixation (Doty et al., 2009), enhancement of phosphate availability (Verma et al., 2001), siderophore production (Rungin et al., 2012), phytohormones synthesis (Tanimoto, 2005), or decreasing ethylene levels (Glick et al., 1998).

Successful phytoremediation of PHC contaminated soils is highly dependent on the selection of an appropriate plantmicrobiome system. Willows (Salix spp.) are fast growing, resilient plant species, which produce sizeable biomass, and create extensive root systems (Schnoor et al., 1995). They are genetically diverse with over 400 cultivar/species and can often be grown from cuttings (Newsholme, 2003; Pulford and Watson, 2003), an advantage for the efficient implementation of this technology in the field. Salix spp. have shown considerable promise in the phytoremediation of organic contaminants (Vervaeke et al., 2003). However, despite recent advances in this field, little is known about the intricate relationships formed between Salix, and its microbiome, knowledge essential to future plant microbiome engineering. Microbial phylotyping can provide critical information for the selection of optimized microbiomes which can lead to enhanced host performance traits such as survival, growth, and fitness (Mueller and Sachs, 2015; Yergeau et al., 2015). The central objective of this study is to understand how contamination affects the microbiome throughout the willow-microbiome holobiont and if this is similar between closely related species of willows. In order to attain this objective, bulk soil, rhizosphere soil, roots, and stems of Salix purpurea cv. Fish Creek and Salix miyabeana cv. SX67 growing in three PHC contamination concentrations were collected for DNA extraction, which was then amplified using bacterial 16S rRNA and fungal ITS genes-specific primers, and sequenced on a Ion Torrent Personal Genome Machine (PGM). Results from this study showed that the contamination concentration significantly influenced the willow microbiome, but not identically for all plant compartments. Fungi and bacteria also responded differently to contamination, willow species, and compartments.

\section{MATERIALS AND METHODS}

\section{Experimental Design and Sampling}

The site is located in Varennes, Québec, Canada $\left(45^{\circ} 43 \mathrm{~N}\right.$, $73^{\circ} 22 \mathrm{~W}$ ) at a closed petrochemical plant. This site was fully operational for 55 years, resulting in land contaminated with a large mixture of PHCs, including PAHs. It is divided into two main areas, one of which is non-contaminated (N1) with $\mathrm{PHC}$ concentrations found below the detection limit according to the Canada-wide standard for petroleum hydrocarbon (PHC) in soil (CWS, 2003) $(<100 \mathrm{mg} / \mathrm{kg})$ in a preliminary survey performed in 2010 and a contaminated area. This study was conducted within the framework of a large phytoremediation pilot project and in addition to the control plot N1, 2 contaminated plots were selected for use, one of which had moderate contamination concentrations (C3), and one with high contamination concentrations (C5). Twelve soil samples from each plot were sent to Maxxam Analytics (Montréal, Québec, Canada) on the 9th of August, 2011 for F1-F4 hydrocarbon analysis, which represents the sum of aliphatic and aromatic hydrocarbon compounds with chain lengths of C6-C50. C3 had concentrations averaging $709 \mathrm{mg} \mathrm{kg}^{-1}$ [ \pm 339 (standard error)] while C5 had concentrations averaging $3590 \mathrm{mg} \mathrm{kg}^{-1}[ \pm 760$ (standard error). Replicates (150) of 11 willow cultivars were planted in each plot in June, 2011 in a randomized block design for more details on the experimental design as well as physicochemical analysis of soil see Bell et al. (2014a)]. Other factors such as soil $\mathrm{pH}$, texture, moisture content, conductivity, and nutrient concentrations could have co-varied with contamination levels and have an effect on the plant microbiome but the very large differences in contamination levels as well as the proximity and similarity of the soils of the different plots likely resulted in the contamination being the main driver.

Sampling of all 3 plots at random for 2 cultivars (Salix purpurea "Fish Creek" and Salix miyabeana "SX67") in triplicates was performed in November 2012, after two full growing seasons 
(average annual temperature of $5.3^{\circ} \mathrm{C}$ and average total yearly precipitation of $1018 \mathrm{~mm}$ ). These cultivars were chosen because of their high yield field performance as well as their dissimilar backgrounds, Fish Creek being of European origin and SX67 being an Asian variety. To characterize the willow microbiome, 4 distinct compartments were targeted: bulk soil $(\sim 200 \mathrm{~g}$ of composite top $10 \mathrm{~cm}$ soil), rhizosphere soil ( $\sim 200 \mathrm{~g}$ of composite root-adhering soil, top $10 \mathrm{~cm}$ soil), root tissue $(\sim 10 \mathrm{~g})$, and stem tissue $(\sim 10 \mathrm{~g})$. A total of 72 samples were collected (3 replicates $\times 2$ cultivar $\times 3$ contamination levels $\times 4$ compartments).

\section{Surface Sterilization of Plant Tissue and DNA Extraction}

Surface sterilization of root and stem tissue samples was first performed in order to cleanse the surface of the plant of any attached microorganisms, as these are not part of the endophytic flora (Escobar, 2012). Samples were rinsed with distilled water to wash off the remaining attached soil, and under aseptic conditions, were immersed in the following washes: $1 \mathrm{~min}$ in $100 \%$ ethanol; $1 \mathrm{~min}$ in $2.5 \% \mathrm{NaOCl} ; 10 \mathrm{~min}$ in $2.5 \% \mathrm{NaOCl}$ under gentle shaking; $1 \mathrm{~min}$ in $100 \%$ ethanol; $30 \mathrm{~s}$ in autoclaved distilled $\mathrm{H}_{2} \mathrm{O}$ (this step was repeated three times). From the final $\mathrm{H}_{2} \mathrm{O}$ wash, $1 \mathrm{ml}$ was plated on $\mathrm{YTS}_{250}$ to verify root surface sterility. Following this, tissue was macerated with a sterile pestle and mortar on a bed of dry ice until a fine powder was produced. DNA extractions on $250 \mathrm{mg}$ of ground plant tissue samples or $250 \mathrm{mg}$ of soil samples were performed using the MoBio PowerSoil ${ }^{\circledR}$ DNA extraction kit (MoBio, Carlsbad, CA, USA). Samples were eluted in $50 \mathrm{uL}$ of autoclaved MilliQ $\mathrm{H}_{2} \mathrm{O}$.

\section{PCR Amplification and Next-Generation Sequencing}

For 16S rRNA gene amplification, soil DNA was amplified by PCR using the primers UnivBactF 9 (5'GAGTTTGATYMTGGCTC- $\left.3^{\prime}\right)$ and BSR534/18 (5'ATTACCGCGGCTGCTGGC-3'), which amplified the V1V2 hypervariable regions, as described in Yergeau et al. (2012). Plant tissue DNA was amplified by PCR, targeting the 16S rRNA gene using the primers 520F (5'-AGCAGCCGCGGTAAT- $3^{\prime}$ ) and 799R2 (5'- CAGGGTATCTAATCCTGTT-3') targeting the V2-V3 hypervariable regions and excluding the chloroplast $16 \mathrm{~S}$ rRNA gene, as described in Edwards et al. (2007). To account for use of different primers and for downstream comparison of samples, a set of samples which were amplified with both primer sets were compared (see supplementary material). A co-inertia analysis was performed, comparing both datasets generated from different primers, and revealed a strong correlation between these datasets and in similar bacterial communities. Hence, we determined that downstream analyses comparing datasets generated with these different primer sets were valid. For the ITS region, soil and plant tissue DNA were amplified using the ITS1F (5'-CTTGGTCATTTAGAGGAAGTAA- $\left.3^{\prime}\right)$ and ITS2 (5'GCTGCGTTCTTCATCGATGC-3') primer set as in Ghannoum et al. (2010). To distinguish between samples, unique multiplex identifier (MID) tags from the extended MID set recommended by Roche (2009) were integrated in the primers, as described in Sanschagrin and Yergeau (2014).
PCR reactions were performed in $20 \mu \mathrm{L}$ volumes containing $12.5 \mu \mathrm{L}$ HotStart Taq Plus Master mix (Qiagen, Germantown, MD, USA), $0.5-2 \mu \mathrm{L}$ of template DNA, $0.4 \mu \mathrm{L}$ of bovine serum albumin from $20 \mathrm{mg} / \mathrm{mL}$ stock and $0.625 \mu \mathrm{L}$ of each forward and reverse primer from $20.0 \mu \mathrm{M}$ stocks. For the $16 \mathrm{~S}$ rRNA primers, cycling conditions were as follows: $5 \mathrm{~min}$ at $95^{\circ} \mathrm{C}, 25$ cycles of $30 \mathrm{~s}$ at $95^{\circ} \mathrm{C}, 30 \mathrm{~s}$ at $55^{\circ} \mathrm{C}$, and $45 \mathrm{~s}$ at $72^{\circ} \mathrm{C}$, and a final elongation step of $10 \mathrm{~min}$ at $72^{\circ} \mathrm{C}$. Amplification of 520F /799R2 amplicons used identical cycling conditions but for 30 cycles and with a $58^{\circ} \mathrm{C}$ annealing temperature. The amplification of a plant tissue sample could only be achieved when raising the number of cycles to 35 . To evaluate the biases that this might cause, another sample that was previously amplified with 30 cycles was also amplified with 35 cycles and sequenced. The ordination coordinates and the community composition of the two datasets were highly similar (see supplementary material), suggesting that cycle number would have a negligible influence in downstream analyses. For the ITS primers, cycling conditions were as follows: $5 \mathrm{~min}$ at $95^{\circ} \mathrm{C}, 30$ cycles of $60 \mathrm{~s}$ at $94^{\circ} \mathrm{C}, 60 \mathrm{~s}$ at $45^{\circ} \mathrm{C}$, and $60 \mathrm{~s}$ at $72^{\circ} \mathrm{C}$, and a final elongation step of $10 \mathrm{~min}$ at $72^{\circ} \mathrm{C}$.

Amplicons were verified on $2 \%$ agarose gels and then gel purified using the PureLink ${ }^{\circledR}$ Quick Gel Extraction Kit (Invitrogen, Life Technologies, Carlsbad, CA, USA) and quantified using the Quant-iT PicoGreen dsDNA assay kit (Invitrogen, Life Technologies). Purified bacterial 16S rRNA gene amplicons were pooled in equimolar ratios separately for soil and endophyte samples, resulting in two pools of 36 samples. The same procedure was followed for the fungal ITS region amplicons, resulting in a grand total of four pools. Each pool was then sequenced following Sanschagrin and Yergeau (2014). Briefly, emulsion PCR was carried out with the Ion One Touch 200 template kit (Life Technologies, Carlsbad, CA) using the OneTouch ES instrument (Life Technologies). The resulting libraries were sequenced on the Ion Torrent PGM system (Life Technologies) using 314 chips with the Ion Sequencing 200 kit.

\section{Sequence Data Treatment}

Sequences were analyzed using the procedure described in Tremblay et al. (2015). Since the bacterial primers used for endophytic and soil communities targeted different regions, they were processed separately as the alignments generated during the procedure would have only overlapped over $\sim 15 \mathrm{bp}$. Soil and endophyte OTU tables were merged for further taxonomic classification and subsequent downstream analyses. OTU tables were rarefied to 1000 reads for bacterial datasets and 306 reads for ITS fungal datasets.

\section{Statistical Analyses}

All statistical analyses were performed in R v.2.15.2 (R Foundation for Statistical Computing; available at http://www. $\mathrm{R}$-project.org). The effect of compartment, contamination and cultivar type on the bacterial and fungal community composition was tested. First, the square roots of UniFrac matrices were used for principal coordinate analyses (PCoA), which were carried out using the "pcoa" function of the "ape" package (Paradis et al., 2004). This unconstrained analysis was used in order to explore the patterns of bacterial and fungal OTU composition across samples. Following this, a distance-based redundancy 
analyses (dbRDA; Legendre and Anderson, 1999a) with the "rda" function and the "anova.cca" of the "vegan" package (Oksanen et al., 2008) was carried out in order to test the significance of these descriptors by multivariate statistical hypothesis testing. This statistical analysis was used to test the significance of the individual descriptors (plant compartment, contamination level, and cultivar type) on multispecies response variables (bacterial/fungal communities) in a multifactorial analysisof-variance model as described in Legendre and Anderson (1999b). A partial dbRDA was used for testing the effect of compartment in order to control for the identity of the trees. The reported adjusted redundancy statistics $R^{2}$ were obtained using the "RsquareAdj" function of the "vegan" package. The relative abundance of specific classified OTUs was represented by samples in a heatmap using the "pheatmap" function in the "pheatmap" package. Venn diagrams were created using the "venn.diagram," "draw.triple.venn," and "draw.quad.venn" functions in the "VennDiagram" package to visualize the number of OTUs that were shared between compartments, contamination, and cultivar type. Venn diagrams of soil and endophyte bacterial samples were produced separately because unique OTUs were formed for each dataset upon clustering.

Co-inertia analysis (Dolédec and Chessel, 1994) was used to determine whether bacterial and fungal communities were similarly affected by contamination and cultivar type. The OTU abundance data was first normalized with a hellinger transformation with the "decostand" function of the "vegan" package. Co-inertia analyses were then performed separately for each compartment with the "dudi.pca" and "coinertia" functions in the "ADE4" package (Dray and Dufour, 2007). The significance was tested by permutation using the "randtest" function in the "ADE4" package. Similarly, co-inertia analysis was used to determine the covariance between rhizosphere microbial communities and endophyte root and stem microbial communities.

The bacterial and fungal alpha diversities in soil and inside plant tissues were compared using a two-way ANOVA test with the "aov" function. When the bacterial soil data failed to meet the assumptions of parametric ANOVA after log, square root, and several power transformations, the non-parametric Kruskal-Wallis one-way test of variance was performed with the "kruskal.test" of the "pgirmess" package. A multiple comparison test, post hoc was then performed between treatments using "kruskalmc" functions of the "pgirmess" package in order to distinguish which treatments were significantly different from one another. An indicator species analysis was performed based on the IndVal index to identify microbial OTUs that were significantly correlated to high contamination using the "multipatt" function in the "labdsv" package.

\section{RESULTS}

\section{Bacterial Community Composition}

The influence of plant compartment, cultivar, and contamination levels on bacterial community composition was visualized using a PCoA ordination and tested for significance using distance-based redundancy analyses. Bacterial communities were primarily influenced by plant compartment (Figure 1A; partial dbRDA: adjusted $R^{2}=0.442, F=20.2, P=0.005$ ), with some minor, but significant effect of contamination levels (Figure 1B; adjusted $\left.R^{2}=0.0255, F=1.93, P=0.0411\right)$. Cultivar had no significant effects on bacterial community structure (Figure 1C; adjusted $\left.R^{2}=-0.00684, F=0.517, P=0.92\right)$.

Bacterial community composition, both in the soil and plant, were primarily dominated by the Proteobacteria (Figure 2A). Soil communities were also colonized by members of the Acidobacteria, Actinobacteria, Bacteroidetes, Chloroflexi, and Gemmatimonadetes phyla. In plant tissues, the Alphaproteobacteria class, of the Proteobacteria phylum, dominated the root samples while the Betaproteobacteria class was predominant in the stem samples. Members of the Actinobacteria, Bacteroidetes, and Firmicutes phyla were also present but relatively not abundant inside plant tissues. The genus Ralstonia, part of the Betaproteobacteria class, dominated the stem samples, representing an average of $43 \%$ of classified genera for these samples, and was excluded from Figure 3 for visual representation purposes.

A striking increase in the relative abundance of Proteobacteria in soil communities was observed as the contamination increased, mainly due to an increase in the Gammaproteobacteria as well as Alphaproteobacteria classes (Figure 2A). This increase in the Proteobacteria is in contrast to the decreases observed in the Actinobacteria and Acidobacteria in soil samples. The increase in the Gammaproteobacteria in the roots and stems was related to increasing relative abundance of Pseudomonas, while it was related to members of the Sinobacteraceae family and the PYR10d3 order in soils (Figure 3). In the root samples, the increase in the Alphaproteobacteria at medium contamination was related to an increased relative abundance of Rhizobium, Sinorhizobium, Sphingobium, and members of the Rhodospirillaceae (Figure 3). The genus Agrobacterium was relatively more abundant in the roots and stems at high contamination levels, while the members of the Oxalobacteraceae increased with contamination in the stem samples (Figure 3).

In line with the tighter clustering of the bulk and rhizosphere soil samples as compared to the plant tissue samples in the PCoA ordinations (Figure 1), bulk and rhizosphere soil samples shared $54 \%$ of their OTUs (Figure 4A) while root and stem endophyte samples only shared 22\% of their OTUs (Figure 4B). Samples from each contamination level harbored unique OTUs, with more shared OTUs between N1-C3 and C3-C5 than N1-C5 (Figure 4C).

\section{Fungal Community Composition}

The contamination level had a more pronounced effect on the fungal communities than on the bacterial communities, as visualized by the clearer clustering of the C5 samples away from the N1 and C3 samples (Figures 5A,B) and the higher significance level in partial dbRDA tests (adjusted $R^{2}=0.0708$, $F=3.70, P=0.005)$. Plant compartment also significantly influenced the fungal community structure (Figure 5A; adjusted $R^{2}=0.0963, F=3.59, P=0.005$ ), while the cultivar type did 
A

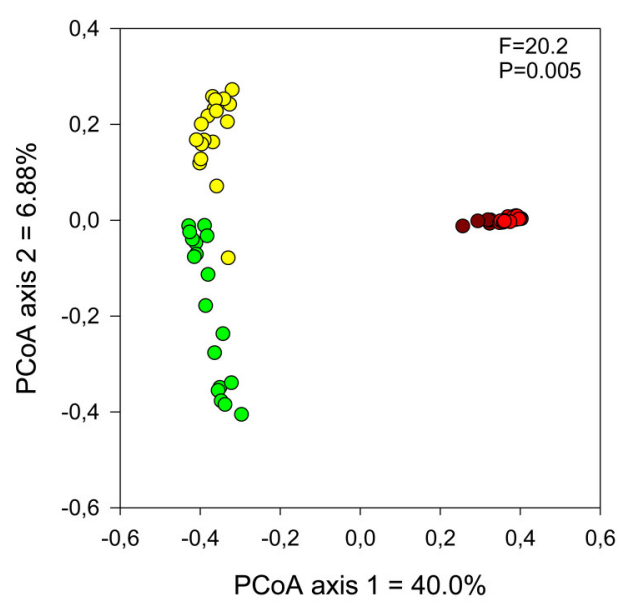

B Contamination

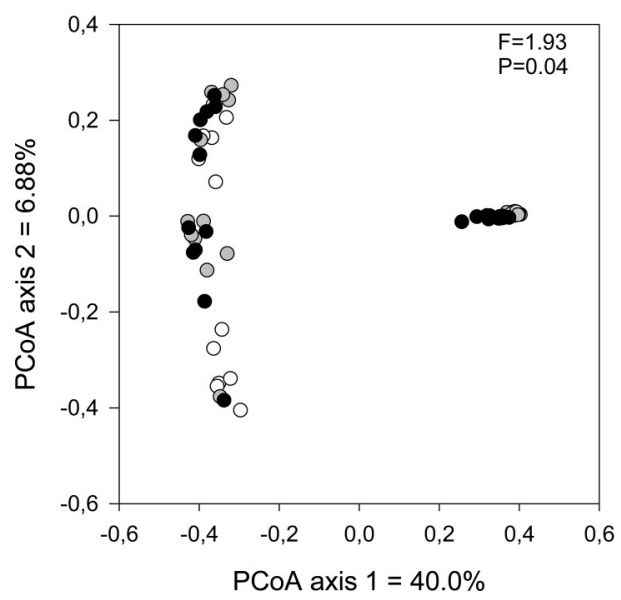

C

Cultivar

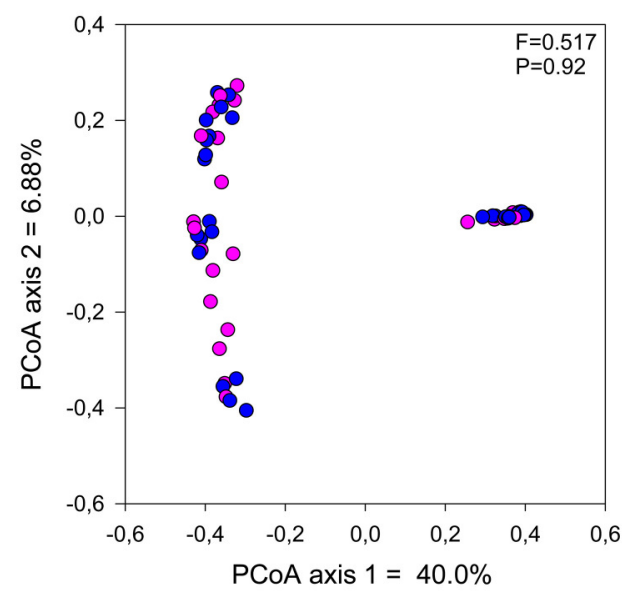

FIGURE 1 | Comparison of bacterial communities by (A) compartment, (B) contamination level, and (C) cultivar type. Influence on soil and endophyte communities shown using principal component analysis based on UniFrac distance measures. $F$-ratio and $P$-values are from distance-based redundancy analyses (Compartment (controlling for the identity of the trees): brown, bulk; red, rhizosphere; yellow, root, and green, stem. Contamination: white, N1; gray, C3, and black, C5. Cultivar: pink, fish, and blue, SX67).

not have a significant effect on fungal communities (Figure 5C; adjusted $\left.R^{2}=0.00534, F=1.38, P=0.0585\right)$.

The soil fungal communities were dominated by the Pezizomycetes and Sordariomycetes with minor contributions from the Dothideomycetes, Agaricomycetes, and Glomeromycetes. The root fungal communities were primarily composed of fungi from the Sordariomycetes while the stem fungal communities were dominated by the Dothideomycetes, Eurotiomycetes, and Leomycetes (Figure 2B). Increasing contamination was associated with increased presence of the Dothideomycetes and Pezizomycetes in soils (Figure 2B). The Agaricomycetes were relatively more abundant in the intermediate contamination soils (C3; Figure 2B). The C3 soils also showed relatively higher abundance of Glomeromycetes, which is the class containing the arbuscular mycorrhizal fungi (AMF; Figure 2B). The genus Funneliformis of the Glomeromycetes showed large increases in relative abundance in the C3 soils (Figure 6). The AMF genera Glomus, Rhizophagus Septoglomus and Paraglomus, were also relatively more abundant in the C3 soils, with stronger effects in the rhizosphere as compared with the bulk soil (Figure 6). The AMF genus Rhizophagus increased its relative abundance with increasing contamination levels both in the soil and in the plant tissues (Figure 6).

Each compartment selected for unique fungal OTUs, with larger overlaps between bulk and rhizosphere soils but also between root and soil samples (Figure 4D). Similar to bacteria, contamination level selected for unique OTUs with $\mathrm{N} 1$ and C5 sharing considerably fewer OTUs than N1-C3 and C3-C5 (Figure 4E). 

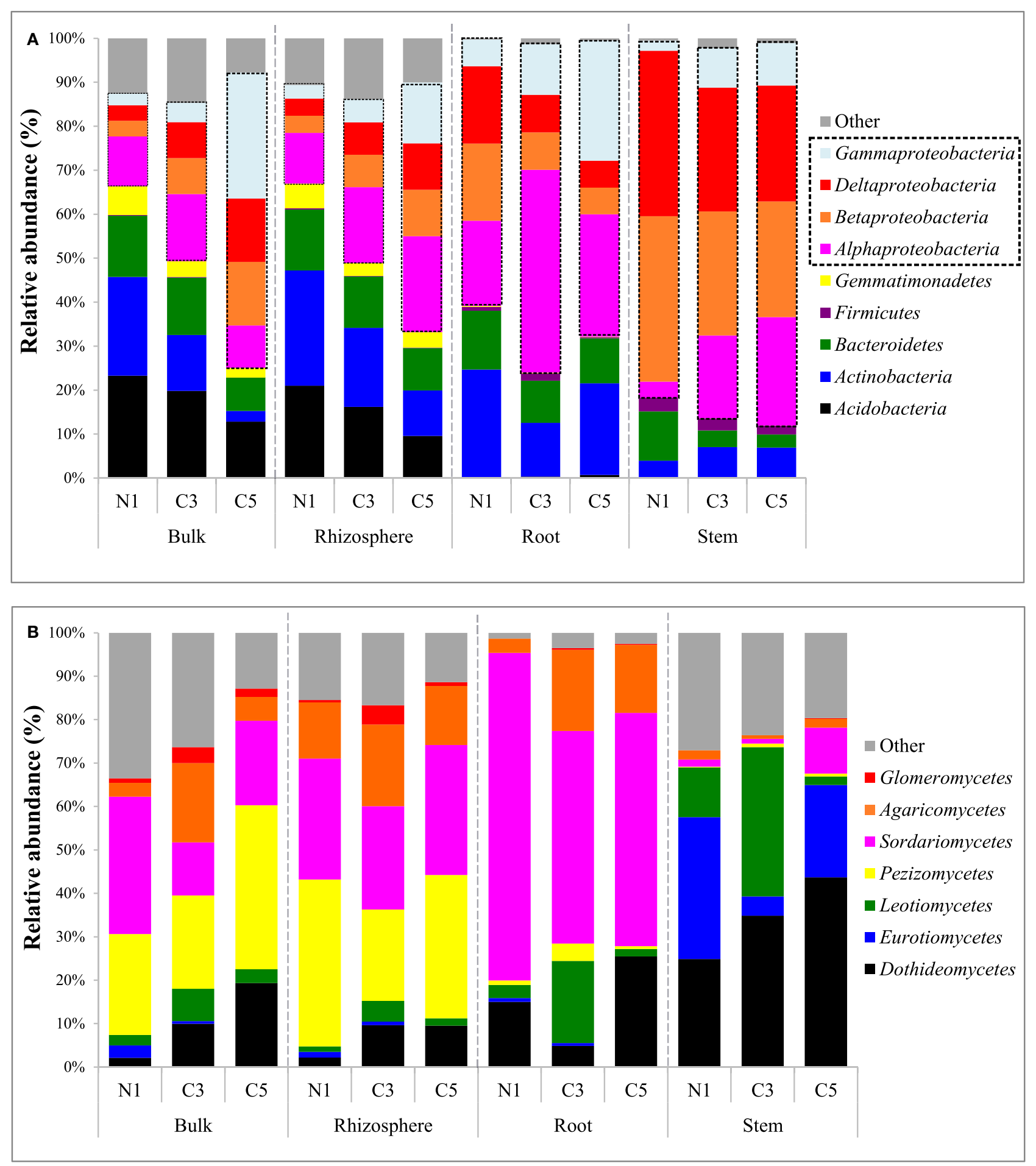

FIGURE 2 | (A) Bacterial community composition of major phyla (and Proteobacteria classes) by averaged samples and (B) fungal community composition of major classes by averaged samples ( $\mathrm{N} 1$, non-contaminated; $\mathrm{C} 3$, moderately contaminated; $\mathrm{C}$, high contamination).

\section{Co-Inertia Analyses}

Co-inertia analysis was used to test whether bacterial and fungal communities were being similarly influenced by contamination and cultivar type. Co-inertia analyses showed that bulk $(R V=$ $0.961, P=0.001)$ and rhizosphere $(R V=0.952, P=0.001)$ bacterial and fungal communities were similarly influenced by 


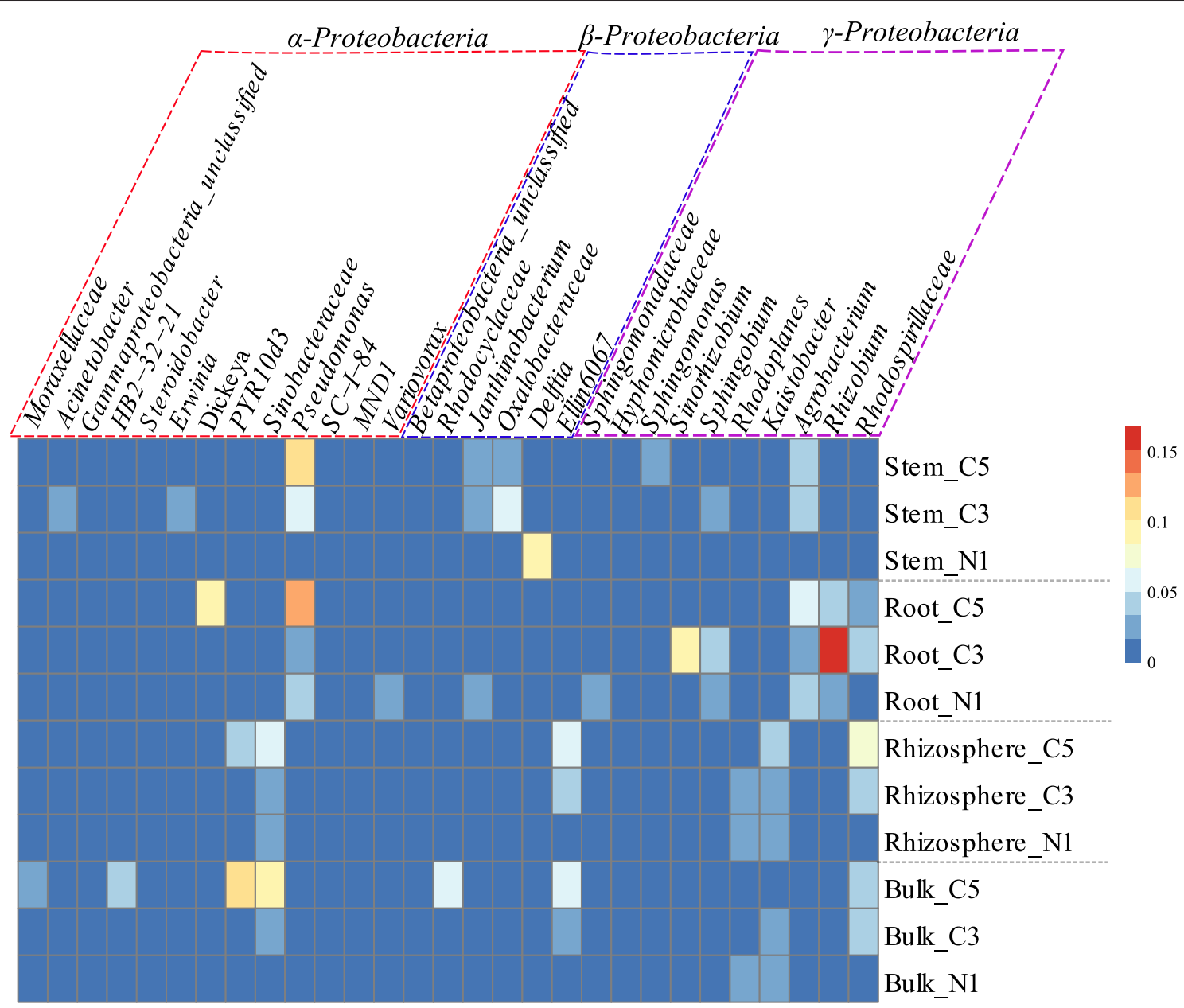

FIGURE 3 | Relative abundance (\%) of the most dominant OTUs of the classes Alphaproteobacteria (purple box), Betaproteobacteria (blue box), and Gammaproteobacteria (red box), by averaged sample represented in a heatmap which was normalized by row, where cells go from blue to red as abundance increases.

these factors while root $(R V=0.814, P=0.573)$ and stem $(R V=0.763, P=0.593)$ communities were not. Similarly, coinertia analyses was used to determine if the bacterial and fungal communities responded similarly to contamination levels across the different plant compartments. The RV coefficients for the co-inertia analyses were significant when comparing bacterial rhizosphere and root communities $(R V=0.913, P=0.001)$ and bacterial rhizosphere and stem communities $(R V=0.874$, $P=0.017)$. For the fungi, significant co-inertia coefficients were only found when comparing fungal rhizosphere and root communities $(R V=0.919, P=0.001)$.

\section{Shannon Diversity}

For bacteria, soil and plant tissue samples were tested separately. For soil samples, Shannon bacterial diversity was significantly influenced by contamination (Kruskal-Wallis, Chisquared $=21.5, P=0.000021)$, with significant differences between $\mathrm{N} 1$ and C3 (post hoc, $Z=1.33, P=0.05$; Table 1). Shannon bacterial diversity in plant tissue samples was significantly influenced by compartment (two-way ANOVA, $F=14.6, P=0.00082)$ and by the interaction term compartment $*$ contamination $(F=3.70, P=0.0399)$. Shannon fungal diversity was significantly influenced by compartment (two-way ANOVA, $F=26.5, P=2.97 \times 10^{-10}$ ), by contamination $(F=3.36, P=0.0431)$, by cultivar $(F=4.85$, $P=0.0324)$ as well as by the interaction term compartment* contamination (two-way ANOVA, $F=2.59, P=0.0298$ ).

\section{Indicator "Species" Analysis}

The indicator species analysis was carried out on OTUs and the taxonomy at the genera level is given for the top 10 indicator OTUs for C3, C5, and C3+C5 plots in Table 2. The full list of indicator OTUs for contamination is provided for bacteria and fungi in Supplementary Tables 1 and 2, respectively. Many of the indicator OTUs could not be classified at the genus level. However, several of these OTUs matched the same genus or family, with some genera such as the ones associated with the Cytophagaceae family comprising 16 of the indicator OTUs 

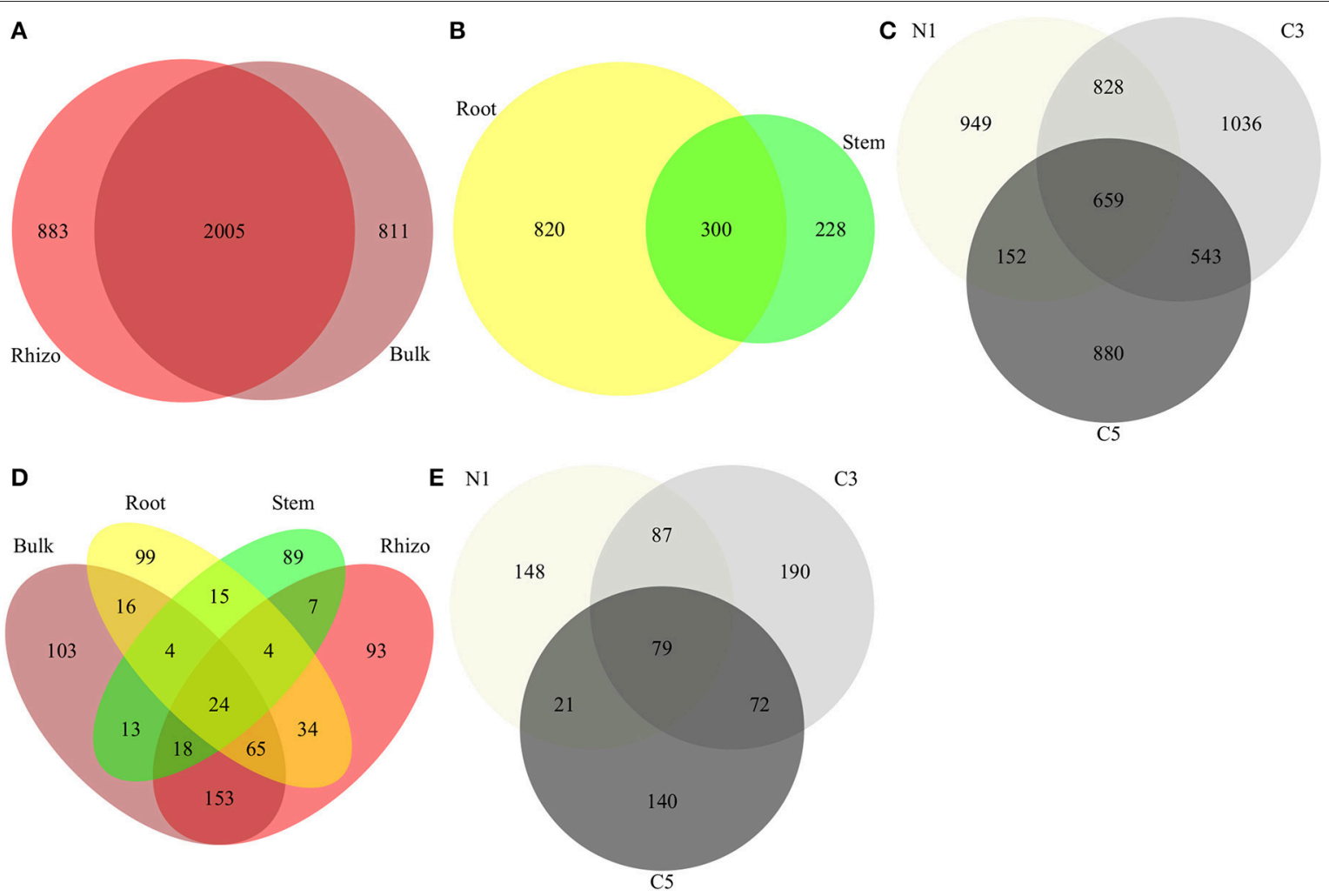

FIGURE 4 | Comparison of communities using Venn diagrams showing OTUs shared between (A) bacterial soil compartment, (B) bacterial endophyte compartments, and (C) bacterial OTUs by contamination level (D) fungal compartments and (E) fungal OTUs by contamination level (Contamination: $\mathrm{N} 1$, no contamination; $\mathrm{C} 3$, medium contamination; $\mathrm{C} 5$, high contamination).

associated with $\mathrm{C} 5$ contamination. Other important contributors in the C3 plot were iiil-15 (9 OTUs), Cytophagaceae (7 OTUs), and Sordariomycetes (5 OTUs). In the C5, PYR10d3 (15 OTUs), Rhodospirillaceae (13 OTUs), Sinobacteraceae (6 OTUs), DS-18 (6 OTUs), Rhodocyclaceae (6 OTUs), and Zopfiella (10 OTUs) played a significant role. Finally, Cytophagaceae (4 OTUs), Rhodospirillaceae (4 OTUs), Geobacter (3 OTUs), and Sinobacteraceae (3 OTUs) were present both in C3 and C5 plots in high numbers.

\section{DISCUSSION}

The microbiome of Salix species growing in PHC-contaminated soil was significantly influenced by contamination with distinct variations amongst compartments and bacterial and fungal community profiles. The effect of contamination influenced not only the rhizosphere soil communities, but also plant tissue microbiomes. The effect of contamination on the bacterial and fungal community composition was less prominent in the rhizosphere and in the plant tissues as compared with the bulk soil, suggesting that the plant environment may be acting as a protective buffer zone for the microbial communities in the soil. For instance the rhizosphere may buffer the effect of contamination on communities because of increased nutrient availability (Berg et al., 2005; el Zahar Haichar et al., 2008;
Badri et al., 2009) and increased expression of hydrocarbon degradation genes (Yergeau et al., 2014). The plant tissues are partly buffered against the adverse effects of contamination by providing a physical barrier against the majority of toxic compounds. It has been shown in previous studies, however, that low-molecular weight, or partially degraded organic contaminants can migrate within the plant and directly influence and shape the plant microbiome (Taghavi et al., 2005; Germaine et al., 2009). In this study we also found that plant tissue microbiomes were composed of some OTUs that were shared with the soil microbiomes. These results suggest that some rhizosphere microorganisms might colonize the endosphere and as such, the effect of contamination in the rhizosphere may be indirectly affecting the endophyte communities. Since these communities interact closely with the host plants, it provides a route for indirect effects of contaminants on plants. Conversely, the stress response of plants to contaminants might partly shape the endophyte communities by modifying the plant environment. An increased understanding of these interactions in the context of contaminated soil could help increase plant tolerance to contaminants resulting in a larger ecological range for plants or better growth and activity under high contamination.

Co-inertia analyses indicated that the bacterial and fungal communities of soil co-varied similarly with varying 
A

Compartment

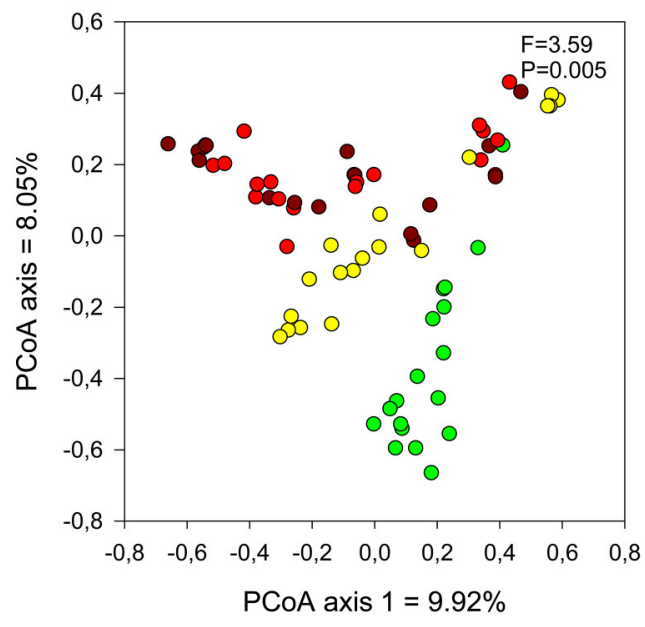

B

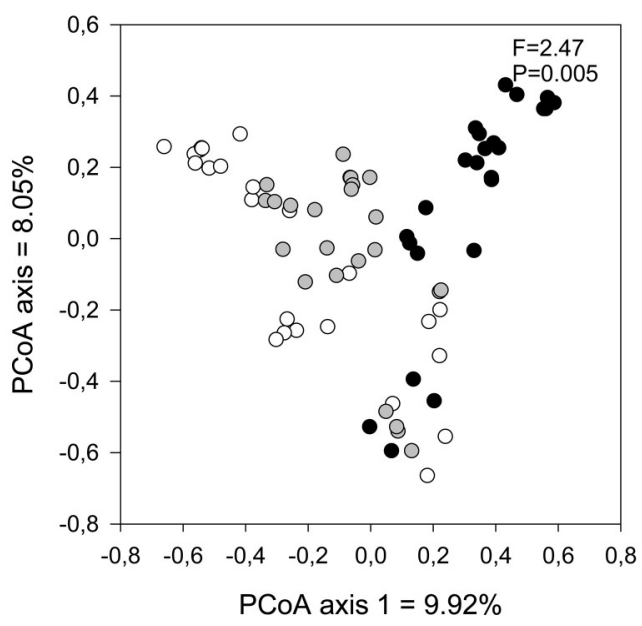

C

Cultivar

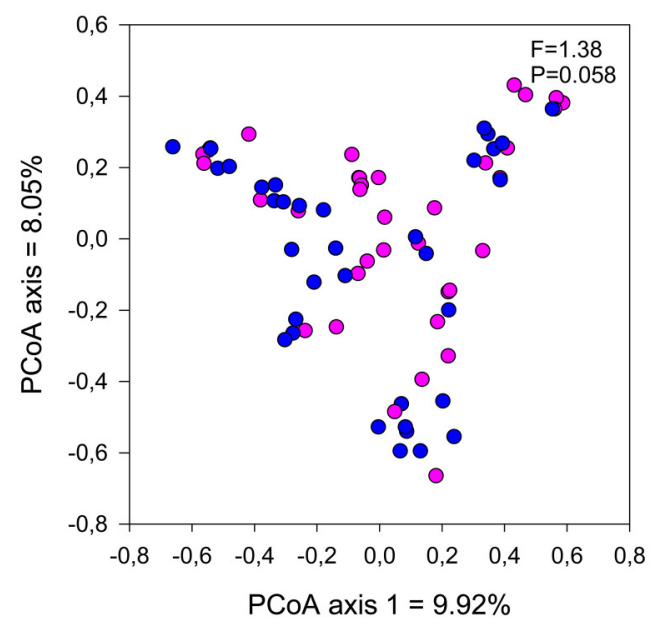

FIGURE 5 | Comparison of fungal communities by (A) compartment, (B) contamination level, and (C) cultivar type. Influence on soil and endophyte communities shown using principal component analysis based on UniFrac distance measures with a distance-based redundancy analysis [Compartment (controlling for the identity of the trees): brown, bulk; red, rhizosphere; yellow, root, and green, stem. Contamination: white, N1; gray, C3 and black, C5. Cultivar: pink, fish, and blue- = SX67].

contamination levels, while plant tissue communities did not. This suggests that bacteria and fungi inhabiting roots and stems do not respond similarly to varying environmental conditions inside plant tissues, probably because of differences in growth patterns, metabolism, or colonization ability. In fact, with changing contamination levels, root, and stem bacterial communities responded similarly to rhizosphere bacterial communities, while the fungal stem communities did not, indicating a larger gap between soil fungi and fungi colonizing plant aerial parts, than for bacteria. Wearn et al. (2012) studied the endophyte communities associated with grassland forbs and found a remarkable difference between the fungal communities found in the root and shoots, suggesting a lack of systemic growth from one tissue to another. Our study suggests that although root tissues were susceptible to colonization by soil fungi, perhaps stem tissues may be more resilient to colonization from the soil.

In contrast to the general decrease in bacterial diversity with increasing contamination levels, soil fungal diversity appeared to be maximal at moderate contamination. This increased diversity corresponded with an increased relative abundance of the arbuscular mycorrhizal fungi (Glomeromycetes). AMF form symbiotic relationships with plants, directly promoting plant growth by capturing nutrients such as phosphorus, sulfur, and nitrogen (Schmidt et al., 2010). AMF increased in relative abundance in the $\mathrm{C} 3$ and for some genera, in the C5 plot, as compared with $\mathrm{N} 1$, both for soil communities and some root communities. This increase is seen very 


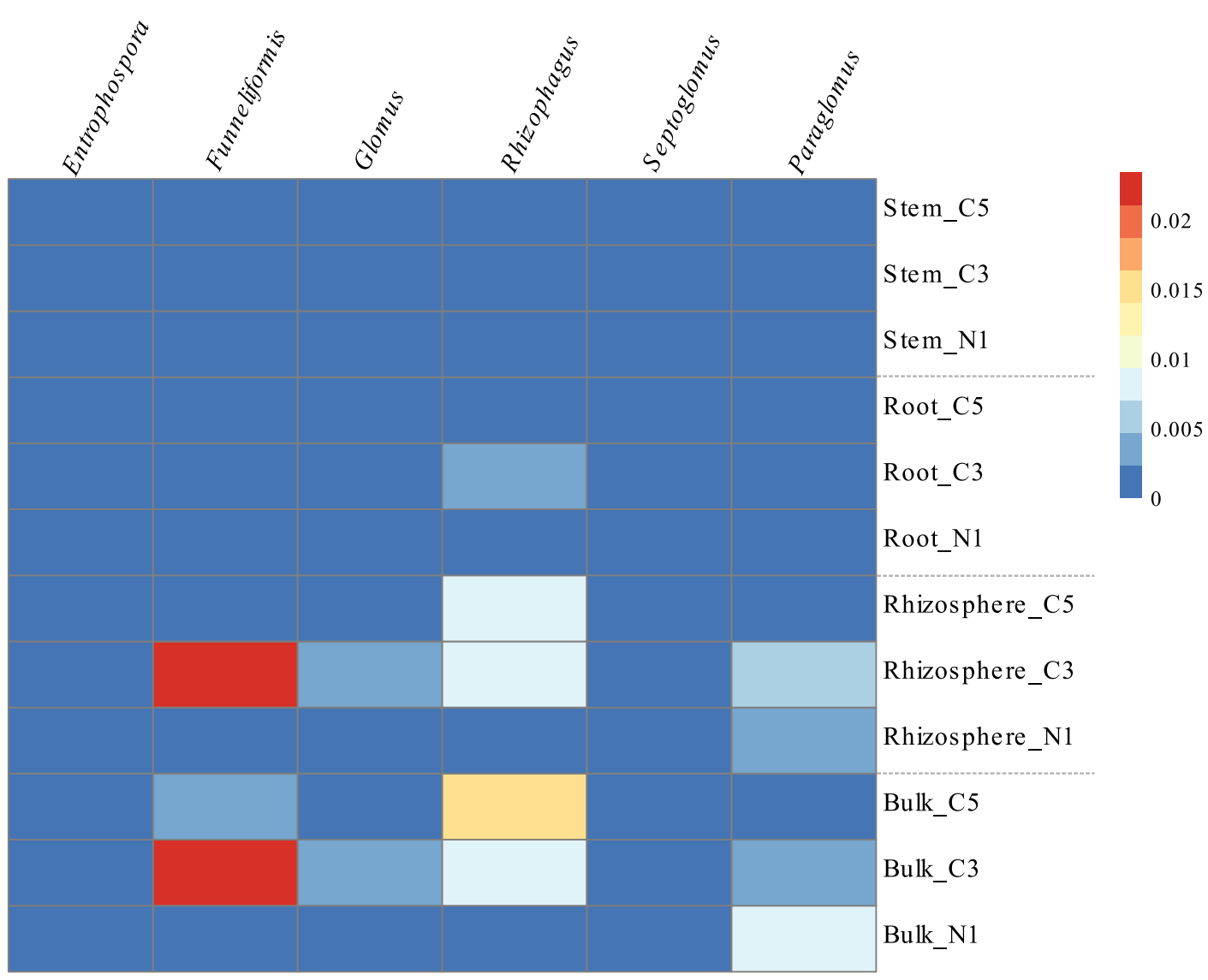

FIGURE 6 | Relative abundance (\%) of the genera comprising the Glomeromycetes class by averaged sample represented in a heatmap, where cells go from blue to red as abundance increases.

TABLE 1 | Shannon diversity of compartment, contamination, and cultivar type of bacterial and fungal communities.

\begin{tabular}{llcc}
\hline & & Bacteria & Fungi \\
\hline Compartment & Bulk & $6.8 \pm 0.63$ & $4.2 \pm 0.79$ \\
& Rhizosphere & $7.0 \pm 0.24$ & $4.3 \pm 0.77$ \\
& Root & $4.8 \pm 1.3$ & $2.6 \pm 1.0$ \\
& Stem & $3.3 \pm 1.2$ & $2.6 \pm 0.85$ \\
\hline Contamination & N1 & $5.4 \pm 2.2$ & $3.4 \pm 1.2$ \\
& C3 & $5.7 \pm 1.7$ & $3.8 \pm 1.4$ \\
& C5 & $5.3 \pm 1.5$ & $3.2 \pm 0.92$ \\
\hline \multirow{2}{*}{ Cultivar } & Fish & $5.5 \pm 1.7$ & $3.2 \pm 1.2$ \\
& SX67 & $5.4 \pm 1.9$ & $3.8 \pm 1.1$ \\
\hline
\end{tabular}

Contamination: N1, no contamination; C3, medium contamination; C5, high contamination.

Values are average \pm standard deviation (compartment: $N=18$; contamination: $N=24$; cultivar type: $N, 36)$.

clearly with the genus Rhizophagus, that may have the potential to degrade hydrocarbons (Calonne et al., 2014). We also observed a marked increase in the Pezizomycetes with contamination, a fungal class that was shown to have a strong association specifically with North American willow cultivars growing in highly $\mathrm{PHC}$-contaminated soils, mainly related to the species Sphaerosporella brunnea, an ectomycorrhizal fungi (EMF; Bell et al., 2014a). Within the endophyte communities, Dothideomycetes, which contains members that are able to degrade hydrocarbons (Bell et al., 2014a) and have been associated with plant health (Popp et al., 2006), also increased with contamination. In line with these findings, the indicator fungal species analysis of contamination identified four important mycorrhizal fungi, Rhizophagus, Funneliformis, Sphaerosporella, and Geopora. Rhizophagus, and Funneliformis, are well known AMF species associated with plant growth promotion (Wu et al., 2014; Padmavathi et al., 2015). Species of Geopora, been found to be the principal EMF colonists of willows planted for restoration in fly ash and have been hypothesized to survive well under harsh environmental conditions (Gehring et al., 2014). These identified genera may be playing an important role in contaminant degradation, plant health and plant growth promotion.

For bacteria, the Proteobacteria, particularly the Gammaproteobacteria, increased considerably with increasing contamination. These findings are consistent with many previous 
TABLE 2 | Top ten results of significant bacterial and fungal indicator species analysis of C3, C5, and combined C3:C5 contamination listed at the highest universally known taxonomy level.

\begin{tabular}{|c|c|c|c|c|c|c|c|c|c|c|c|c|}
\hline & IndVal & $P$-value & Rank & Taxonomy & IndVal & $P$-value & Rank & Taxonomy & IndVal & $P$-value & Rank & Taxonomy \\
\hline & & & C3 & & & & C5 & & & & $\mathrm{C} 3+\mathrm{C5}$ & \\
\hline & 0.683 & 0.001 & Family & Rhodospirillaceae & 0.701 & 0.001 & Family & Alteromonadaceae & 0.677 & 0.001 & Family & Sinobacteraceae \\
\hline \multirow[t]{9}{*}{ Bacteria } & 0.645 & 0.001 & Class & Deltaproteobacteria & 0.701 & 0.001 & Phylum & Gemmatimonadetes & 0.66 & 0.001 & Class & Betaproteobacteria \\
\hline & 0.639 & 0.001 & Genus & Inquilinus & 0.677 & 0.001 & Class & Gammaproteobacteria & 0.634 & 0.003 & Class & Betaproteobacteria \\
\hline & 0.62 & 0.009 & Phylum & Chloroflexi & 0.674 & 0.001 & Class & Gammaproteobacteria & 0.62 & 0.001 & Order & Rhizobiales \\
\hline & 0.614 & 0.028 & Class & Betaproteobacteria & 0.672 & 0.001 & Phylum & Gemmatimonadetes & 0.615 & 0.046 & Genus & Novosphingobium \\
\hline & 0.612 & 0.001 & Class & Acidobacteria & 0.671 & 0.001 & Class & Betaproteobacteria & 0.612 & 0.001 & Genus & Hyphomicrobium \\
\hline & 0.598 & 0.003 & Family & Rhodospirillaceae & 0.67 & 0.001 & Family & Cytophagaceae & 0.612 & 0.002 & Family & Cytophagaceae \\
\hline & 0.594 & 0.001 & Class & Betaproteobacteria & 0.669 & 0.001 & Phylum & Acidobacteria & 0.61 & 0.005 & Genus & Steroidobacter \\
\hline & 0.584 & 0.001 & Phylum & Acidobacteria & 0.654 & 0.001 & Class & Gammaproteobacteria & 0.596 & 0.002 & Family & Streptomycetaceae \\
\hline & 0.584 & 0.001 & Phylum & Acidobacteria & 0.645 & 0.001 & Family & Rhodospirillaceae & 0.58 & 0.032 & Family & Rhodospirillaceae \\
\hline \multirow[t]{10}{*}{ Fungi } & 0.673 & 0.001 & Family & Lasiosphaeriaceae & 0.938 & 0.001 & Genus & Zopfiella & 0.721 & 0.023 & Genus & Alternaria \\
\hline & 0.647 & 0.001 & Genus & Funneliformis & 0.828 & 0.001 & Kingdom & Fungi & 0.673 & 0.003 & Family & Thelephoraceae \\
\hline & 0.645 & 0.001 & Genus & Phaeosphaeriopsis & 0.825 & 0.001 & Genus & Epicoccum & 0.661 & 0.002 & Genus & Geopora \\
\hline & 0.607 & 0.001 & Phylum & Ascomycota & 0.807 & 0.001 & Genus & Zopfiella & 0.66 & 0.042 & Genus & Cladosporium \\
\hline & 0.603 & 0.002 & Phylum & Ascomycota & 0.791 & 0.001 & Genus & Zopfiella & 0.598 & 0.032 & Genus & Alternaria \\
\hline & 0.602 & 0.001 & Order & Helotiales & 0.786 & 0.001 & Genus & Sphaerosporella & 0.559 & 0.006 & Genus & Tomentella \\
\hline & 0.592 & 0.001 & Genus & Phaeoseptoria & 0.761 & 0.001 & Genus & Zopfiella & 0.54 & 0.006 & Genus & Rhizophagus \\
\hline & 0.577 & 0.001 & Genus & Mycoarthris & 0.758 & 0.001 & Genus & Leptosphaeria & 0.54 & 0.003 & Phylum & Ascomycota \\
\hline & 0.577 & 0.001 & Genus & Apodus & 0.742 & 0.001 & Phylum & Ascomycota & 0.5 & 0.018 & Phylum & Ascomycota \\
\hline & 0.542 & 0.004 & Family & Pyronemataceae & 0.709 & 0.001 & Genus & Zopfiella & 0.433 & 0.044 & Family & Thelephoraceae \\
\hline
\end{tabular}

Contamination: N1, no contamination; C3, medium contamination; C5, high contamination.

studies that have demonstrated the hydrocarbon degradation potential of many members of this class (Arun et al., 2008; Sopeña et al., 2013). Notably, the family Sinobacteraceae (Gutierrez et al., 2013) and the order PYR10d3 (Singleton et al., 2006), which have been associated with hydrocarbon degradation in previous studies, increased with contamination. Indeed, Sinobacteraceae were also identified as indicator taxa for the highly contaminated samples. Of interest, the Alphaproteobacteria class increased with contamination selectively in the rhizosphere soil. The Rhodospirillaceae family, previously reported to increase its expression of the alkane 1-monooxygenase gene (alkB, C5-C16 alkane substrate) in the rhizosphere of willows (Pagé et al., 2015), was found here to be relatively more abundant in highly contaminated rhizosphere soil. The indicator species analysis of contamination also identified other interesting potential players from different classes of the Proteobacteria phylum including the Rhodocyclaceae family, which contains members that can degrade pyrene (Singleton et al., 2006) and phenanthrene (Singleton et al., 2005). Geobacter species are important anaerobic bacteria that have the ability to oxidize organic compounds such as hydrocarbons and halogenated compounds (Holmes et al., 2007). The anaerobic micro niches in the soil could accommodate these species and as they were recurrently associated with contamination, these microorganisms could play a role in anaerobic hydrocarbon degradation. Further studies aiming at isolating the bacteria and fungi identified here would be necessary to confirm their precise roles in phytoremediation and their potential for plant inoculation approaches.

Endophyte community shifts were also highly linked to the Proteobacteria. Notably, the genera Pseudomonas, Dickeya, and Steroidobacter of the Gammaproteobacteria class and Sinorhizobium, Sphingobium, and Rhizobium of the Alphaproteobacteria class increased their relative abundance in the roots with contamination. In addition to being part of the natural willow endophyte microbiome (Doty et al., 2009), previous studies have found that these classes contain many important plant-growth promoting organisms, harboring multiple plant-beneficial properties (Bruto et al., 2014). The indicator species analysis of contamination identified bacteria in the microbiome such as the Cytophagaceae (Xu et al., 2014) and Rhodospirillaceae (Madigan et al., 1984), which are known nitrogen fixers and may be associated with plant health. Interestingly, the Streptomyces, identified as significant indicators of $\mathrm{C} 5$, as well as both $\mathrm{C} 3$ and $\mathrm{C} 5$, has species that can promote fungal growth and mycorrhizal formation (Tokala et al., 2002; Tarkka et al., 2008). Members of this genus have also demonstrated plant growth promoting abilities by effectively helping plants mobilize and acquire nutrients, control plant pathogens and produce siderophores (Verma et al., 2011). In addition, this analysis also identified some genera that were previously associated with hydrocarbon degradation within the endophyte communities. Past studies have found that Novosphingobium has been linked with the degradation of 
aromatic compounds such as phenol, aniline, nitrobenzene, and phenanthrene (Liu et al., 2005) as well as other PAHs (Sohn et al., 2004). In addition, Sphingomonadaceae have been associated with hydrocarbon degradation (Liang and LloydJones, 2010) while Steroidobacter contains members that are steroidal hormone degrading bacteria (Fahrbach et al., 2008). The increased relative abundance of these microorganisms with increasing contamination in the plant microbiome could suggest that the plant host may be recruiting these organisms for survival in these highly toxic environments. Alternatively, this increase could also be explained by an increase in nutrient (i.e., hydrocarbon) availability within the plant tissues as a result of the translocation of contaminants within the plant tissues.

\section{CONCLUSIONS}

This study has provided a unique view into the microbiome of willows growing in PHC-contaminated soils. We found that contamination was the primary factor structuring not only the rhizosphere, but also plant tissue microbiomes. Plant tissue microbiomes were composed of OTUs shared with the soil microbiomes, but also of unique OTUs. The presence of the plant provided a protective buffer zone against contamination in the rhizosphere and in the root and stem tissue, resulting in less drastic effects of increasing contamination on microbial community composition, as compared with the bulk soil. Species diversity generally decreased as contamination increased with the exception of increased fungal diversity at moderate contamination, which was linked with increased AMF relative abundance. In addition, increasing contamination resulted in shifts in the composition of the microbiome, favoring putative hydrocarbon degraders and microorganisms putatively associated with beneficial plant growth effects. The indicator species analysis identified several key microorganisms associated with contamination. Further isolation, characterization, and inoculation studies, however, will be essential to test out their

\section{REFERENCES}

Arun, A., Raja, P. P., Arthi, R., Ananthi, M., Kumar, K. S., and Eyini, M. (2008). Polycyclic aromatic hydrocarbons (PAHs) biodegradation by basidiomycetes fungi, Pseudomonas isolate, and their cocultures: comparative in vivo and in silico approach. Appl. Biochem. Biotechnol. 151, 132-142. doi: 10.1007/s12010008-8160-0

Badri, D. V., Weir, T. L., Van Der Lelie, D., and Vivanco, J. M. (2009). Rhizosphere chemical dialogues: plant-microbe interactions. Curr. Opin. Biotechnol. 20, 642-650. doi: 10.1016/j.copbio.2009.09.014

Bell, T. H., El-Din Hassan, S., Lauron-Moreau, A., Al-Otaibi, F., Hijri, M., Yergeau, E., et al. (2014a). Linkage between bacterial and fungal rhizosphere communities in hydrocarbon-contaminated soils is related to plant phylogeny. ISME J. 8, 331-343. doi: 10.1038/ismej.2013.149

Bell, T. H., Joly, S., Pitre, F. E., and Yergeau, E. (2014b). Increasing phytoremediation efficiency and reliability using novel omics approaches. Trends Biotechnol. 32, 271-280. doi: 10.1016/j.tibtech.2014.02.008

Berg, G., Zachow, C., Lottmann, J., Götz, M., Costa, R., and Smalla, K. (2005). Impact of plant species and site on rhizosphere-associated fungi antagonistic to Verticillium dahliae kleb. Appl. Environ. Microbiol. 71, 4203-4213. doi: 10.1128/AEM.71.8.4203-4213.2005 ability to stimulate remediation processes. Our study has shown that contamination affects the microbiome of willows, but with differences between plant compartments and between bacteria and fungi. This information will prove to be important to devise and engineer optimal plant microbiomes for the efficient phytoremediation of organic contamination.

\section{AUTHOR CONTRIBUTIONS}

ST designed and carried out this study, collected data, performed the analysis, and wrote the manuscript. EY contributed to design, data processing, statistical analyses, and preparation of the manuscript. JT participated in data processing and analysis. PL participated in data and statistical analyses. LW participated in design and manuscript revision. CG participated in the design, planning, data analysis, and manuscript revision.

\section{FUNDING}

This work was supported by the Genome Canada and Genome Québec funded GenoRem Project.

\section{ACKNOWLEDGMENTS}

We would like to thank Dr. Terrence Bell, Fahad Al Otaibi and Claude Masson for their assistance with field sampling as well as Christine Maynard and Sylvie Sanschagrin for their contribution in the laboratory. We also like to thank Pétroment for providing access to the Varennes field site.

\section{SUPPLEMENTARY MATERIAL}

The Supplementary Material for this article can be found online at: http://journal.frontiersin.org/article/10.3389/fmicb. 2016.01363

Bruto, M., Prigent-Combaret, C., Muller, D., and Moënne-Loccoz, Y. (2014). Analysis of genes contributing to plant-beneficial functions in plant growthpromoting rhizobacteria and related Proteobacteria. Sci. Rep. 4:6261. doi: 10.1038/srep06261

Calonne, M., Fontaine, J., Debiane, D., Laruelle, F., Grandmougin-Ferjani, A., and Lounès-Hadj Sahraoui, A. (2014). The arbuscular mycorrhizal Rhizophagus irregularis activates storage lipid biosynthesis to cope with the benzo [a] pyrene oxidative stress. Phytochemistry 97, 30-37. doi: 10.1016/j.phytochem.2013.10.014

CWS, P. (2003). Canada Wide Standard for Petroleum Hydrocarbons in Soil. Winnipeg. Version CCME 3, 12.

Dolédec, S., and Chessel, D. (1994). Co-inertia analysis: an alternative method for studying species-environment relationships. Freshw. Biol. 31, 277-294. doi: 10.1111/j.1365-2427.1994.tb01741.x

Doty, S. L., Oakley, B., Xin, G., Kang, J. W., Singleton, G., Khan, Z., et al. (2009). Diazotrophic endophytes of native black cottonwood and willow. Symbiosis 47, 23-33. doi: 10.1007/BF03179967

Dray, S., and Dufour, A.-B. (2007). The ade4 package: implementing the duality diagram for ecologists. J. Stat. Softw. 22, 1-20. doi: 10.18637/jss.v022.i04

Edwards, J. E., Huws, S. A., Kim, E. J., and Kingston-Smith, A. H. (2007). Characterization of the dynamics of initial bacterial colonization of 
nonconserved forage in the bovine rumen. FEMS Microbiol. Ecol. 62, 323-335. doi: 10.1111/j.1574-6941.2007.00392.x

Escobar, P. (2012). Development, Production and Application of Alder-Frankia Symbionts for the Remediation and Vegetation of Oil Sands Process-Affected Materials (OSPM) in Athabasca. M.Sc. thesis, McGill University.

El Amrani, A., Dumas, A.-S., Wick, L. Y., Yergeau, E., and Berthomé, R. (2015). "Omics" insights into PAH degradation toward improved green remediation biotechnologies. Environ. Sci. Technol. 49, 11281-11291. doi: 10.1021/acs.est.5b01740

el Zahar Haichar, F., Marol, C., Berge, O., Rangel-Castro, J. I., Prosser, J. I., Balesdent, J., et al. (2008). Plant host habitat and root exudates shape soil bacterial community structure. ISME J. 2, 1221-1230. doi: 10.1038/ismej.2008.80

Fahrbach, M., Kuever, J., Remesch, M., Huber, B. E., Kämpfer, P., Dott, W., et al. (2008). Steroidobacter denitrificans gen. nov., sp. nov., a steroidal hormonedegrading gammaproteobacterium. Int. J. Syst. Evol. Microbiol. 58, 2215-2223. doi: 10.1099/ijs.0.65342-0

Gehring, C. A., Mueller, R. C., Haskins, K. E., Rubow, T. K., and Whitham, T. G. (2014). Convergence in mycorrhizal fungal communities due to drought, plant competition, parasitism and susceptibility to herbivory: consequences for fungi and host plants. Front. Microbiol. 5:306. doi: 10.3389/fmicb.2014.00306

Germaine, K. J., Keogh, E., Ryan, D., and Dowling, D. N. (2009). Bacterial endophyte-mediated naphthalene phytoprotection and phytoremediation. FEMS Microbiol. Lett. 296, 226-234. doi: 10.1111/j.1574-6968.2009.01637.x

Ghannoum, M. A., Jurevic, R. J., Mukherjee, P. K., Cui, F., Sikaroodi, M., Naqvi, A., et al. (2010). Characterization of the oral fungal microbiome (mycobiome) in healthy individuals. PLoS Pathog. 8:e1000713. doi: 10.1371/journal.ppat.1000713

Glick, B. R., Penrose, D. M., and Li, J. (1998). A model for the lowering of plant ethylene concentrations by plant growth-promoting bacteria. J. Theor. Biol. 190, 63-68. doi: 10.1006/jtbi.1997.0532

Günther, T., Dornberger, U., and Fritsche, W. (1996). Effects of ryegrass on biodegradation of hydrocarbons in soil. Chemosphere 33, 203-215. doi: 10.1016/0045-6535(96)00164-6

Gutierrez, T., Green, D. H., Nichols, P. D., Whitman, W. B., Semple, K. T., and Aitken, M. D. (2013). Polycyclovorans algicola gen. nov., sp. nov., an aromatichydrocarbon-degrading marine bacterium found associated with laboratory cultures of marine phytoplankton. Appl. Environ. Microbiol. 79, 205-214. doi: 10.1128/AEM.02833-12

Holmes, D. E., O’Neil, R. A., Vrionis, H. A., N'guessan, L. A., Ortiz-Bernad, I., Larrahondo, M. J., et al. (2007). Subsurface clade of Geobacteraceae that predominates in a diversity of Fe (III)-reducing subsurface environments. ISME J. 1, 663-677. doi: 10.1038/ismej.2007.85

Huang, X.-D., El-Alawi, Y., Penrose, D. M., Glick, B. R., and Greenberg, B. M. (2004). A multi-process phytoremediation system for removal of polycyclic aromatic hydrocarbons from contaminated soils. Environ. Pollut. 130, 465-476. doi: 10.1016/j.envpol.2003.09.031

Kowalchuk, G. A., Yergeau, E., Leveau, J. H., Sessitsch, A., Bailey, M., Liu, W., et al. (2010). "Plant-associated microbial communities," in Environmental Molecular Microbiology, eds J. K. Jansson and L. Wen-Ts (Norwich, UK: Horizon Scientific Press), 131-148.

Legendre, P., and Anderson, M. J. (1999a). Distance-based redundancy analysis: testing multispecies responses in multifactorial ecological experiments. Ecol. Monogr. 69, 1-24. doi: 10.1890/0012-9615(1999)069[0001:DBRATM] 2.0.CO;2

Legendre, P., and Anderson, M. J. (1999b). Distance-based redundancy analysis: testing multispecies responses in multifactorial ecological experiments. Ecol. Monogr. 69, 1-24.

Liang, Q., and Lloyd-Jones, G. (2010). Sphingobium scionense sp. nov., an aromatic hydrocarbon-degrading bacterium isolated from contaminated sawmill soil. Int. J. Syst. Evol. Microbiol. 60, 413-416. doi: 10.1099/ijs.0.008144-0

Liu, Z.-P., Wang, B.-J., Liu, Y.-H., and Liu, S.-J. (2005). Novosphingobium taihuense sp. nov., a novel aromatic-compound-degrading bacterium isolated from Taihu Lake, China. Int. J. Syst. Evol. Microbiol. 55, 1229-1232. doi: 10.1099/ijs.0.63468-0

Madigan, M., Cox, S. S., and Stegeman, R. A. (1984). Nitrogen fixation and nitrogenase activities in members of the family Rhodospirillaceae. J. Bacteriol. 157, 73-78.
Mueller, U. G., and Sachs, J. L. (2015). Engineering microbiomes to improve plant and animal health. Trends Microbiol. 23, 606-617. doi: 10.1016/j.tim.2015.07.009

Newsholme, C. (2003). Willows: The Genus Salix. Portland, OR: Timber Press Incorporated.

Oksanen, J., Kindt, R., Legendre, P., O’Hara, B., Simpson, G. L., Solymos, P., et al. (2008). Vegan: Community Ecology Package. version 1.15-4.

Padmavathi, T., Dikshit, R., and Seshagiri, S. (2015). Effect of Rhizophagus spp. and plant growth-promoting Acinetobacter junii on Solanum lycopersicum and Capsicum annuum. Braz. J. Bot. 38, 273-280. doi: 10.1007/s40415-015-0144-z

Pagé, A. P., Yergeau, É., and Greer, C. W. (2015). Salix purpurea stimulates the expression of specific bacterial xenobiotic degradation genes in a soil contaminated with hydrocarbons. PLOS ONE 10:e0132062. doi: 10.1371/journal.pone.0132062

Paradis, E., Claude, J., and Strimmer, K. (2004). APE: analyses of phylogenetics and evolution in R language. Bioinformatics 20, 289-290. doi: 10.1093/bioinformatics/btg412

Popp, N., Schlömann, M., and Mau, M. (2006). Bacterial diversity in the active stage of a bioremediation system for mineral oil hydrocarbon-contaminated soils. Microbiology 152, 3291-3304. doi: 10.1099/mic.0.29054-0

Pradhan, S. P., Conrad, J., Paterek, J. R., and Srivastava, V. J. (1998). Potential of phytoremediation for treatment of PAHs in soil at MGP sites. J. Soil Contam. 7, 467-480. doi: 10.1080/10588339891334401

Pulford, I. D., and Watson, C. (2003). Phytoremediation of heavy metalcontaminated land by trees-a review. Environ. Int. 29, 529-540. doi: 10.1016/S0160-4120(02)00152-6

Reichenauer, T. G., and Germida, J. J. (2008). Phytoremediation of organic contaminants in soil and groundwater. ChemSusChem 1, 708-717. doi: $10.1002 /$ cssc. 200800125

Roche, D. (2009). "Using multiplex identifier (MID) adaptors for the GS FLX titanium chemistry-extended MID set," in Technical Bulletin: Genome Sequencer FLX System (Branchburg, NJ: Roche), 2-4.

Rungin, S., Indananda, C., Suttiviriya, P., Kruasuwan, W., Jaemsaeng, R., and Thamchaipenet, A. (2012). Plant growth enhancing effects by a siderophoreproducing endophytic streptomycete isolated from a Thai jasmine rice plant (Oryza sativa L. cv. KDML105). Antonie Van Leeuwenhoek 102, 463-472. doi: 10.1007/s10482-012-9778-z

Sanschagrin, S., and Yergeau, E. (2014). Next-generation sequencing of 16S ribosomal RNA Gene amplicons. J. Vis. Exp. 90:e51709. doi: 10.3791/51709

Schlaeppi, K., and Bulgarelli, D. (2014). The plant microbiome at work. Mol. Plant-Microbe Interact. 28, 212-217. doi: 10.1094/MPMI-10-14-0334-FI

Schmidt, B., Gaşpar, S., Camen, D., Ciobanu, I., and Sumălan, R. (2010). Arbuscular mycorrhizal fungi in terms of symbiosis-parasitism continuum. Commun. Agric. Appl. Biol. Sci. 76, 653-659.

Schnoor, J. L., Light, L. A., McCutcheon, S. C., Wolfe, N. L., and Carreia, L. H. (1995). Phytoremediation of organic and nutrient contaminants. Environ. Sci. Technol. 29, 318A-323A. doi: 10.1021/es00007a747

Siciliano, S. D., Germida, J. J., Banks, K., and Greer, C. W. (2003). Changes in microbial community composition and function during a polyaromatic hydrocarbon phytoremediation field trial. Appl. Environ. Microbiol. 69, 483-489. doi: 10.1128/AEM.69.1.483-489.2003

Singer, A. C., Crowley, D. E., and Thompson, I. P. (2003). Secondary plant metabolites in phytoremediation and biotransformation. Trends Biotechnol. 21, 123-130. doi: 10.1016/S0167-7799(02)00041-0

Singleton, D. R., Powell, S. N., Sangaiah, R., Gold, A., Ball, L. M., and Aitken, M. D. (2005). Stable-isotope probing of bacteria capable of degrading salicylate, naphthalene, or phenanthrene in a bioreactor treating contaminated soil. Appl. Environ. Microbiol. 71, 1202-1209. doi: 10.1128/AEM.71.3.1202-1209.2005

Singleton, D. R., Sangaiah, R., Gold, A., Ball, L. M., and Aitken, M. D. (2006). Identification and quantification of uncultivated Proteobacteria associated with pyrene degradation in a bioreactor treating PAH-contaminated soil. Environ. Microbiol. 8, 1736-1745. doi: 10.1111/j.1462-2920.2006.01112.x

Sohn, J. H., Kwon, K. K., Kang, J.-H., Jung, H.-B., and Kim, S.-J. (2004). Novosphingobium pentaromativorans sp. nov., a high-molecular-mass polycyclic aromatic hydrocarbon-degrading bacterium isolated from estuarine sediment. Int. J. Syst. Evol. Microbiol. 54, 1483-1487. doi: 10.1099/ijs.0.02945-0 Sopeña, F., Laiz, L., Morillo, E., Sanchez-Trujillo, M. A., Villaverde, J., Jurado, V., et al. (2013). Phenanthrene Biodegradation by Pseudomonas xanthomarina 
isolated from an aged contaminated soil. Clean Soil Air Water 42, 785-790. doi: 10.1002/clen.201300247

Sun, M., Fu, D., Teng, Y., Shen, Y., Luo, Y., Li, Z., et al. (2011). In situ phytoremediation of PAH-contaminated soil by intercropping alfalfa (Medicago sativa L.) with tall fescue (Festuca arundinacea Schreb.) and associated soil microbial activity. J. Soils Sediments 11, 980-989. doi: 10.1007/s11368-011-0382-Z

Taghavi, S., Barac, T., Greenberg, B., Borremans, B., Vangronsveld, J., and van der Lelie, D. (2005). Horizontal gene transfer to endogenous endophytic bacteria from poplar improves phytoremediation of toluene. Appl. Environ. Microbiol. 71, 8500-8505. doi: 10.1128/AEM.71.12.8500-8505.2005

Tanimoto, E. (2005). Regulation of root growth by plant hormones-roles for auxin and gibberellin. CRC. Crit. Rev. Plant Sci. 24, 249-265. doi: $10.1080 / 07352680500196108$

Tarkka, M. T., Lehr, N.-A., Hampp, R., and Schrey, S. D. (2008). Plant behavior upon contact with Streptomycetes. Plant Signal. Behav. 3, 917-919. doi: $10.4161 /$ psb.5996

Tokala, R. K., Strap, J. L., Jung, C. M., Crawford, D. L., Salove, M. H., Deobald, L. A., et al. (2002). Novel plant-microbe rhizosphere interaction involving Streptomyces lydicus WYEC108 and the pea plant (Pisum sativum). Appl. Environ. Microbiol. 68, 2161-2171. doi: 10.1128/AEM.68.5.2161-2171.2002

Tremblay, J., Singh, K., Fern, A., Kirton, E. S., He, S., Woyke, T., et al. (2015). Primer and platform effects on 16S rRNA tag sequencing. Front. Microbiol. 6:771. doi: 10.3389/fmicb.2015.00771

Verma, S. C., Ladha, J. K., and Tripathi, A. K. (2001). Evaluation of plant growth promoting and colonization ability of endophytic diazotrophs from deep water rice. J. Biotechnol. 91, 127-141. doi: 10.1016/S0168-1656(01) 00333-9

Verma, V. C., Singh, S. K., and Prakash, S. (2011). Bio-control and plant growth promotion potential of siderophore producing endophytic Streptomyces from Azadirachta indica A. Juss. J. Basic Microbiol. 51, 550-556. doi: 10.1002/jobm.201000155

Vervaeke, P., Luyssaert, S., Mertens, J., Meers, E., Tack, F. M., and Lust, N. (2003). Phytoremediation prospects of willow stands on contaminated sediment: a field trial. Environ. Pollut. 126, 275-282. doi: 10.1016/S0269-7491(03)00189-1
Wearn, J. A., Sutton, B. C., Morley, N. J., and Gange, A. C. (2012). Species and organ specificity of fungal endophytes in herbaceous grassland plants. J. Ecol. 100, 1085-1092. doi: 10.1111/j.1365-2745.2012.01997.x

Wu, Q.-S., Cao, M.-Q., Zou, Y.-N., and He, X.-,H. (2014). Direct and indirect effects of glomalin, mycorrhizal hyphae, and roots on aggregate stability in rhizosphere of trifoliate orange: Sci. Rep. 4:5823. doi: 10.1038/srep05823

Xu, L., Zeng, X.-C., Nie, Y., Luo, X., Zhou, E., Zhou, L., et al. (2014). Pontibacter diazotrophicus sp. nov., a Novel Nitrogen-Fixing Bacterium of the Family Cytophagaceae. PLoS ONE 9:e92294. doi: 10.1371/journal.pone.0092294

Yateem, A., Balba, M., El-Nawawy, A., and Al-Awadhi, N. (1999). Experiments in phytoremediation of Gulf War contaminated soil. Soil Groundwater Cleanup 2, 31-38.

Yergeau, E., Bell, T. H., Champagne, J., Maynard, C., Tardif, S., Tremblay, J., et al. (2015). Transplanting soil microbiomes leads to lasting effects on willow growth, but not on the rhizosphere microbiome. Front. Microbiol. 6:1436. doi: 10.3389/fmicb.2015.01436

Yergeau, E., Lawrence, J. R., Sanschagrin, S., Waiser, M. J., Korber, D. R., and Greer, C. W. (2012). Next-generation sequencing of microbial communities in the Athabasca River and its tributaries in relation to oil sands mining activities. Appl. Environ. Microbiol. 78, 7626-7637. doi: 10.1128/AEM.02036-12

Yergeau, E., Sanschagrin, S., Maynard, C., St-Arnaud, M., and Greer, C. W. (2014). Microbial expression profiles in the rhizosphere of willows depend on soil contamination. ISME J. 8, 344-358. doi: 10.1038/ismej.2013.163

Conflict of Interest Statement: The authors declare that the research was conducted in the absence of any commercial or financial relationships that could be construed as a potential conflict of interest.

Copyright (c) 2016 Tardif, Yergeau, Tremblay, Legendre, Whyte and Greer. This is an open-access article distributed under the terms of the Creative Commons Attribution License (CC BY). The use, distribution or reproduction in other forums is permitted, provided the original author(s) or licensor are credited and that the original publication in this journal is cited, in accordance with accepted academic practice. No use, distribution or reproduction is permitted which does not comply with these terms. 